\title{
An Electrochemical Study of Surface Oxidation and Collectorless Flotation of Pyrite
}

\author{
Dongping Tao ${ }^{1, *}$, Yue Wang ${ }^{1}$ and Lin $\mathrm{Li}^{2}$ \\ ${ }^{1}$ School of Mining Engineering, University of Science and Technology Liaoning, Anshan, Liaoning \\ 114051, China. \\ ${ }^{2}$ College of Chemical and Environmental Engineering, Shandong University of Science and \\ Technology, Qingdao, Shandong 266590, China \\ *E-mail: dptao@qq.com
}

doi: $10.20964 / 2018.06 .32$

Received: 27 October 2017 / Accepted: 6 April 2018 / Published: 10 May 2018

\begin{abstract}
Pyrite is a common sulfide mineral and its surface oxidation and natural hydrophobicity play an important role in determining flotation performance for many minerals, particularly for sulfides and coal. In this study freshly fractured electrodes have been used to investigate the surface oxidation of fresh pyrite surface and collectorless microflotation tests were performed to study its natural hydrophobicity. Chronoamperometry performed on in-situ fractured electrodes demonstrated that pyrite oxidation takes place at potentials of $-0.28 \mathrm{~V}$ (SHE) at $\mathrm{pH} 9.2$ and $0 \mathrm{~V}$ at $\mathrm{pH} 4.6$, considerably lower than previously assumed. Incipient oxidation at slightly more positive potentials produce a hydrophobic sulfur-rich species, most likely a polysulfide or metal-deficient sulfide, which imparts natural surface hydrophobicity to pyrite. Collectorless microflotation test results have indicated that pyrite acquires considerable floatability upon superficial oxidation. The collectorless flotation recovery of pyrite is determined by the relative amounts of polysulfide, soluble species, and insoluble species produced during oxidation, which depends on solution $\mathrm{pH}$ and potential.
\end{abstract}

Keywords: chronoamperometry, collectorless flotation, freshly fractured electrodes, hydrophobicity, oxidation, pyrite, voltammetry

\section{FULL TEXT}

(C) 2018 The Authors. Published by ESG (www.electrochemsci.org). This article is an open access article distributed under the terms and conditions of the Creative Commons Attribution license (http://creativecommons.org/licenses/by/4.0/). 